Resenha 



\section{John B. Watson, \\ O CUIDADO PSICOLÓGICO DO INFANTE E DA CRIANÇA: POSSÍVEIS CONSEQÜÊNCIAS PARA O MOVIMENTO BEHAVIORISTA \\ Por: Bruno Angelo Strapasson ${ }^{\star}$}

WATSON, J. B.; WATSON, R. R. Psychological care of infant and child. New York: Norton, 1928.

\section{John B. Watson e a divulgação científica em Psicologia}

John B. Watson é uma figura muito conhecida na história da psicologia. A maioria dos autores o aponta como fundador do movimento behaviorista. Entretanto, poucos sabem que ele foi um dos grandes defensores da transformação da psicologia numa disciplina aplicada (BUCKLEY, 1989; COHEN, 1979; MORRIS; TODD, 1999), movimento esse por vezes indicado como responsável pela independência da psicologia em relação à filosofia (ABIB, 1998). Além de um grande defensor da psicologia como um campo de aplicação, e talvez justamente por defender este compromisso, Watson foi um grande disseminador dessa área do saber para o público leigo (COHEN, 1979). Dentre as dezenas de entrevistas no rádio, ${ }^{1}$ textos em jornais e em periódicos literários, Watson escreveu dois livros que tinham o grande público como alvo, The ways of Behaviorism [Os Caminhos do Behaviorismo] (WATSON, 1928) e o Psychological Care of Infant and Child [Cuidado Psicológico do Infante e da Criança - doravante apenas Psychological Care] publicado há exatos 80 anos (WATSON, J.; WATSON, R., 1928) e traduzido para o português em 1934 (WATSON, J.; WATSON, R., 1934[1928]), texto este que pode ser considerado um dos primeiros livros de divulgação científica na psicologia e que será o foco desta resenha.

O caráter polêmico do livro Psychological Care e o impacto que teve na disseminação da psicologia em geral e do Behaviorismo em específico ${ }^{2}$ justificam essa resenha e devem servir de alerta para os profissionais que se dedicam à divulgação científica em psicologia hoje, explicando, portanto, a retomada dessa obra 80 anos depois de sua publicação.

Watson ficou muito conhecido pela publicação do chamado "manifesto behaviorista": um conjunto de palestras publicadas em forma de artigo em 1913 no qual defendeu o abandono da introspecção e a adoção da observação direta do comportamento como o único método possível para uma psicologia científica. O manifesto behaviorista coordenou muitas das manifestações esparsas que já

\footnotetext{
* Possui graduação em Psicologia pela Universidade Federal do Paraná (2004) e mestrado em Psicologia do Desenvolvimento e Aprendizagem pela Universidade Estadual Paulista (UNESPBauru - 2008). É atualmente professor das Faculdades Integradas do Brasil - UNIBRASIL. Endereço: Faculdades Integradas do Brasil, Escola de Saúde. Rua Konrad Adenauer, 442 Tarumã. CEP.: 82820-540 - Curitiba, PR - Brasil.

E-mail: brunoastr@gmail.com
} 
vinham criticando o método introspectivo e se tornou um marco histórico na psicologia. A grande reivindicação de Watson, tanto no manifesto quanto em outras de suas obras (eg. WATSON, J., 1928, 1930) era a transformação da psicologia, através da adoção da observação do comportamento como método privilegiado, numa ciência capaz de prever e controlar o comportamento, e que, portanto, teria grandes aplicações práticas. Com esses propósitos, (1) o apelo à observação e experimentação do comportamento, (2) a rejeição de conceitos mentais inobserváveis e (3) a aplicação prática dos conhecimentos produzidos pela psicologia tornaram-se elementos marcantes de sua proposta.

Em 1920, devido a certas condutas pessoais inaceitáveis à época (relacionamento extraconjugal com uma de suas alunas, Rosalie Reiner, colaboradora no projeto do Psychological Care e com quem posteriormente viria a casar) Watson é convidado a retirar-se da Johns Hopkins University onde lecionava. Após esse ocorrido, muda-se para Nova York e, não tendo conseguido outras posições em universidades, começa a trabalhar com marketing na J. Walter Thompson. Entretanto, sendo amplamente conhecido como um dos grandes nomes da psicologia da época e ganhando alguma publicidade com o trabalho com marketing, é convidado a falar sobre diversos assuntos do cotidiano e da psicologia no rádio e em periódicos populares, expondo, via de regra, opiniões polêmicas sobre esses assuntos. ${ }^{3}$ A partir de então, Watson diminui suas publicações para o público acadêmico e investe gradativamente mais em publicações para o público leigo de tal modo que, em 1925, seus contatos com a academia resumem-se a algumas palestras, resenhas de livros acadêmicos e a co-orientação de Mary Cover Jones num trabalho não concluído. Cohen (1979) e Logue (1994) sugerem que, ao afastar-se do ambiente acadêmico e privado da crítica promovida por esse ambiente, Watson vai gradativamente extrapolando seus resultados e interpretações para ambientes e situações onde seus dados não são suficientes para sustentar suas teorias. Se considerarmos que nas primeiras décadas do século XX a avaliação da repercussão de uma fala no rádio era o número de cartas recebidas pela emissora comentando um programa ou entrevista (LAFOLLETTE, 2002), o que provavelmente também era verdade para os periódicos populares impressos, é razoável supor que após sair da Johns Hopkins University o controle exercido pela crítica acadêmica foi transferido gradativamente para a repercussão que suas falas provocavam no público leigo até porque seu trabalho com marketing exigia certa visibilidade (BUCKLEY, 1989; LOGUE, 1994), essa transferência se torna importante porque o reconhecimento acadêmico era contingente a adequada formulação de teorias baseadas em dados e a repercussão no público leigo era contingente a discrepância entre os padrões culturais vigentes e a proposta publicada. O Psychological Care é um dos seus últimos livros de divulgação publicados e, portanto, pode-se supor que seja o mais influenciado pela repercussão pública em detrimento do reconhecimento acadêmico. Além disso, os estudos mais conhecidos e disseminados de Watson são aqueles sobre o condicionamento de emoções em crianças e o campo mais direto para a aplicação de tais estudos é a criação de filhos, o que torna o Psychological Care a obra de divulgação científica mais importante de Watson segundo seu próprio projeto de psicologia (WATSON, 1930). 


\section{O Psychological Care of Infant and Child}

O Psychological Care é composto de sete capítulos seguindo uma ordem bem formulada do conteúdo. Versando sobre a metodologia behaviorista de pesquisa (cap. I), o condicionamento e descondicionamento do medo (cap. II), do amor (cap. III), da ira (cap. IV), orientações sobre rotinas diurnas e noturnas para as crianças (cap. V), educação sexual (cap. VI) e finalizando com alertas sobre a aplicação de suas proposições ser adequada apenas à cultura norte-americana da época (cap. VII), o casal Watson acredita demonstrar como é possível a criação científica dos filhos, aliás, tornar a criação de filhos uma profissão baseada no conhecimento científico é a grande esperança dos Watson para a correção dos caminhos que a civilização americana seguia em sua época:

Ninguém sabe o suficiente para criar uma criança. O mundo seria consideravelmente melhor se parássemos de ter filhos por vinte anos (exceto aqueles criados com propósitos experimentais) e começássemos novamente com fatos suficientes para se fazer o trabalho com algum grau de habilidade e precisão (WATSON J.; WATSON, R., 1928, p.12).

O principal argumento do casal Watson que sustenta essa reivindicação é sua constatação de que raramente se encontravam crianças felizes no início do século XX na América. Eles não indicam quais foram as bases para essa constatação, mas definem o que seria, para eles, uma criança feliz:

[...] uma criança que nunca chora a menos que furado por uma ponta, ilustrativamente falando que se perde no trabalho e nas brincadeiras que rapidamente aprende a superar pequenas dificuldades em seu ambiente sem correr para a mãe, pai, enfermeira ou outro adulto [...] que aplica aqueles hábitos de polidez, conforto e limpeza de modo que os adultos fiquem dispostos a ficar perto dele ao menos parte do dia; crianças que se disponham a ficar perto dos adultos sem lutar incessantemente para serem notadas [...] que passa pela adolescência tão bem equipado que essa adolescência é apenas um trecho dos anos férteis e que consegue finalmente entrar na fase adulta tão fortificado, com trabalho estável e hábitos emocionais, que nenhuma adversidade pode sobrepujá-lo (WATSON, J.; WATSON, R., 1928, p. 9-10).

Desse modo, parece claro que os Watson não estavam preocupados em proporcionar condições para crianças subjetivamente mais felizes. A reivindicação dos Watson é que as crianças sejam capazes de superar as dificuldades da vida de modo independente e sem demonstrar sofrimento, e essa seria uma concepção científica de felicidade. 
J. B. Watson e R. R. Watson iniciam o Psychological Care reivindicando a criação científica dos filhos e utilizam os seus famosos estudos sobre o condicionamento emocional de crianças para sustentar suas proposições. Nesses estudos, realizados na Johns Hopkins, os Watson tentam demonstrar que são poucos os estímulos capazes de provocar emoções em crianças recém nascidas, apenas barulhos altos e perda de equilíbrio causam medo, ser impedido de movimentar-se causa ira e o toque na pele, principalmente nos lábios e órgãos genitais, causa amor.

Baseado nos experimentos de condicionamento e descondicionamento que descrevem no livro, J. B. Watson e R. R. Watson (1928) defendem que todos os outros estímulos que provocam reações emocionais ganham essas propriedades por emparelhamento com os estímulos previamente mencionados, derivando dessa idéia orientações sobre como se evitar o desenvolvimento de medos, ódio e o que ele chamava de "amor excessivo".

Entretanto, ainda que o casal Watson tenha defendido a criação estritamente científica de filhos e baseado parte de suas orientações em experimentos bastante originais e até avançados para a época, muitas das orientações presentes no livro não derivam dos seus experimentos. Os ideais a serem alcançados na criação dos filhos, por exemplo, não são dedutíveis de suas pesquisas. A título de exemplo, os Watson defendem que a criança ideal deve ter suas emoções sob controle (o que só poderia ser ensinado pelo comportamento científico dos pais):

$\mathrm{O}$ medo pode ser ensinado tão facilmente quanto ler e escrever, construir com blocos ou desenhar. Ele pode ser ensinado adequadamente ou inadequadamente. Quando ensinada cientificamente a vida emocional está então sob “controle" (WATSON, J.; WATSON, R., 1928, p. 68).

Além disso, pode-se encontrar no decorrer do livro indicações para se evitar a masturbação e a punição física bem como conversar abertamente sobre reprodução com as crianças, de preferência mostrando fotos de animais ou livros de obstetrícia, prescrições essas que não foram pesquisadas diretamente (WATSON, J.; WATSON, R., 1928).

A mais controversa prescrição dos Watson é sobre o manejo dos "hábitos de amor". Como dito anteriormente, eles defendiam que o amor era um comportamento condicionado por meio do emparelhamento de certos objetos e pessoas ao toque na pele do bebê, especialmente nas regiões genital e labial. Entretanto, eles observaram que quando os objetos de amor da criança (as pessoas que as tocavam) saiam de perto, estas ficavam muito perturbadas e não conseguiam continuar as tarefas em que estavam envolvidas. Baseado nessa observação (e implicitamente defendendo que crianças independentes são mais saudáveis) os Watson alertam que as conseqüências de se supercondicionar respostas de amor nas crianças faria delas adultos inseguros e dependentes:

[...] o amor excessivo cria um invalidismo. Quando adultos temos muitos mal estares e dores vagos [...] Na exata medida em que você dispensa tempo mimando e acariciando [...] 
você furta da criança o tempo que ela deveria estar dedicando na manipulação do universo, adquirindo técnica com os dedos, mãos e braços [...] Mimar é um experimento perigoso (WATSON, J.; WATSON, R., 1928, p. 76-80).

De posse dessas previsões, o casal Watson sugere que nunca se beije ou abrace os filhos e que as cuidadoras das crianças sejam trocadas com freqüência ou bem treinadas para fazer o mesmo. Os contatos físicos deveriam se resumir à higiene das crianças (o que deveria ser-lhes ensinado o quanto antes). Caso a mãe sentisse muita necessidade de beijar o filho que o fizesse na testa antes de dormir. Para os Watson, as mães que exageram no contato físico (que eram a maioria das mães americanas) com o filho o fazem motivadas por suas próprias necessidades de amor (que devem ter sido condicionadas na infância dessas mães), pois, para ele, apertos de mão e tapinhas nas costas são suficientes para se expressar carinho e afeto. A previsão de que o "supercondicionamento" do amor não era um evento saudável, e especialmente a previsão de que esses eventos levariam ao desenvolvimento de um adulto inseguro e dependente, não são derivados diretamente de observações ou experimentos, elas parecem mais ser expressão da influência dos ideais de comportamento infantil que os Watson adotaram (o que por sua vez também não são baseados em dados observados e que segundo os próprios autores eram radicalmente contrários às práticas culturais vigentes (WATSON, J.; WATSON, R., 1928). Talvez motivados por essas discrepâncias entre os dados que sustentaram sua proposta científica e as prescrições para a criação de filhos é que Morris e Todd (1999, p. 56) avaliam sabiamente que o Psychological Care "continua sendo impresso apenas como uma curiosidade histórica. Em todo caso, pouco dos seus conselhos são derivados do Behaviorismo".

\section{A interpretaÇão do livro}

O Psychological Care surge num contexto cultural propício à sua disseminação. A América do Norte da virada para o século XX passava por transformações importantes na percepção que se tinha dos filhos: as crianças (e sua saúde física e psicológica) deixavam de ser apenas fruto da vontade divina para tornarem-se responsabilidade das famílias e da sociedade, que precisava agora aprender a como exercer o cuidado "correto" dos filhos (STEARNS, 2004). O livro do casal Watson se insere neste contexto acompanhado de muitas outras obras sobre a criação de filhos, mas algumas peculiaridades de sua proposta, apesar de aparentemente promissoras à época, ${ }^{4}$ mostraram-se simplesmente inalcançáveis. Crianças independentes e que não apresentam respostas emocionais não foram o resultado da aplicação dos princípios do behaviorismo watsoniano e diversas reações contrárias às reivindicações de distanciamento afetivo surgiram, levando ao abandono precoce da adoção das prescrições behavioristas de cuidado parental (STEARNS, 2004).

Apesar de suas propostas terem tido pouco suporte dos resultados encontrados no seu empreendimento de psicologia científica, os Watson reiteram diversas vezes em seu livro que suas prescrições são resultado direto da ciência 
behaviorista. Assim, o fracasso da aplicação das propostas dos Watson à criação de filhos pode ter repercutido como um atestado da ineficiência de sua proposta psicológica reforçando o contexto crítico e polêmico que envolveu todo o movimento behaviorista (CARRARA, 2005).

É verdade que Watson faz ressalvas às suas próprias posições. No início do Psychological Care diz: "o behaviorista ainda não sabe o suficiente hoje para fazer um trabalho satisfatório. Estamos apenas começando a acreditar que há algo como o cuidado psicológico da criança" (WATSON, J.; WATSON, R., 1928, p. 3-4) e em 1936 admite que sabia pouco sobre a criação de crianças para ter escrito o que escreveu. Entretanto, essas ressalvas não foram suficientes para acalentar a crítica.

\section{Conseqüências do Psychological Care}

Ao Psychological Care parece caber perfeitamente a análise que Logue (1994) faz da produção de Watson. Logue (1994) avalia que Watson adotou um discurso progressivamente mais polêmico, radical e retórico durante sua obra, especialmente após ter saído da John Hopkins. Juntamente com outras afirmações radicais e retóricas, como a bem conhecida declaração "dêem-me uma dúzia de crianças saudáveis [...]" (WATSON, J., 1930, p. 104), as prescrições do Psychological Care parecem ter contribuído para que o behaviorismo fosse conhecido pelos psicólogos e pelo público leigo da época e, pouco tempo depois, rechaçado quando verificada a impossibilidade de concretização de sua proposta científica. Ainda que Watson tenha feito proposições mais arrazoadas no início de sua carreira, seus últimos escritos ganharam fama de tal modo que é deles que se retiram as citações mais freqüentes em manuais de psicologia (TODD, 1994), criando assim uma caricatura do behaviorismo que é freqüentemente estendida a todo o movimento behaviorista a despeito das diferenças radicais entre o behaviorismo clássico de Watson e as outras formas de behaviorismo (CARRARA, 2005). Ademais, sugere-se que o Psychological Care é emblemático da extrapolação apressada de princípios psicológicos para prescrições em contextos aplicados, o que deve servir de contra-exemplo. Caso a publicação de textos como esse não seja evitada, dificilmente alcançaremos um contexto cultural que legitime a psicologia como ciência e profissão. No que diz respeito ao Psychological Care e o Behaviorismo, é justamente o contrário que parece ter acontecido.

\section{Notas}

${ }^{1}$ Essa, inclusive, uma das maiores formas de publicidade da ciência no início do século XX, especialmente da medicina e da psicologia (LAFOLLETTE, 2002).

${ }^{2}$ Especialmente a contribuição que teve no fomento das controvérsias que rondaram o behaviorismo na época e que, segundo Carrara (2005), ajudam a explicar o trajeto histórico da crítica e aceitação do behaviorismo desde então.

${ }^{3}$ Essa era, na verdade, uma forma de ganhar maior popularidade - demandada por sua nova profissão - e de ganhar algum dinheiro numa época em que se restabelecia financeiramente após o divórcio.

${ }^{4}$ Stearns (2004) indica que a proposta behaviorista watsoniana para o cuidado parental, com seu enfoque na mudança do ambiente da criança, foi a primeira capaz de dar uma alternativa concreta ao cuidado disciplinar e de saúde (com respeito aos freqüentes acidentes domésticos) das crianças estadunidenses. 


\section{REFERÊNCIAS}

ABIB, J. A. D. Virada social na historiografia da psicologia e independência institucional da psicologia. In: . Psicologia: Teoria e Pesquisa, Brasília, v. 14, n. 1, p. 77-84, 1998.

BUCKLEY, K. W. Mechanical Man: John Broadus Watson and the beginnings of behaviorism. New York: Guilford, 1989.

CARRARA, K. Behaviorismo Radical: crítica e metacrítica. São Paulo: UNESP, 2005.

COHEN, D. J. B. Watson: the founder of behaviorism. London: Routledge \& Kegan Paul, 1979.

LAFOLLETTE, M. C. A survey of science content in U.S. radio broadcasting, 1920s through 1940s: scientists speak in their own voices. Science Communication, USA, v. 24, n. 1, p. 4-33, 2002.

LOGUE, A. W. Watson's behaviorist manifesto: Past positive and current negative consequences. In: MORRIS, E. K.; TODD, J. T. (Ed.). Modern Perspectives on John B. Watson and classical Behaviorism. Westport: Greenwood, 1994. p. 109-123.

MORRIS, E. K.; TODD, J. T. Watsonian Behaviorism. In: DONOHUE, W. O.; KITCHENER, R. (Ed.). Handbook of Behaviorism. San Diego: Academic Press, 1999, p. 16-72.

STEARNS, P. N. Anxious Parents: a history of modern childrearing in America. New York: New York University Press. 2004.

TODD, J. T. What Psychology has to say about John B. Watson: clasical behaviorism in psychology textbooks, 1920-1989. In: MORRIS, E. K.; TODD, J. T. (Ed.). Modern Perspectives on John B. Watson and classical Behaviorism. Westport: Greenwood: 1994. p. 75-107.

WATSON, J. B. Psychology as a behaviorist views it. Psychological Review, [S.1.], v. 20, p. 158-177, 1913.

. The ways of Behaviorism. New York: Harper \& Brothers, 1928.

. Behaviorism, $2^{\text {nd }}$ ed. London: Kegan Paul, Trench, Trubner \& Co, 1930.

. John Broadus Watson. In: MURCHISON, C. (Ed.). A History of

Psychology in Autobiography. Worcester: Clark University, 1936. p. 271-281. 
Bruno Angelo Strapasson

WATSON, J. B.; WATSON, R. R. Psychological care of infant and child. New York: Norton, 1928.

Marisa, 1934.

Educação Psicológica da Primeira Infância (1928). Rio de Janeiro:

Recebido em: maio de 2008

Aceito em: dezembro de 2008 